\title{
$O$ adolescente e suas representaçôes sociais: apontamentos sobre a importância do contexto histórico
}

I ${ }^{1}$ Fernando Lionel Quiroga, ${ }^{2}$ Maria Sylvia de Souza Vitalle I

Resumo: O propósito desta discussão consiste em problematizar os modos de representação social da adolescência. A tradição cientifica, especificamente a partir de Erikson (1976), favoreceu a representação social segundo a qual a adolescência é um período de passagem entre a infância e a idade adulta, isto é, um período marcado pela instabilidade, crise e turbulência cuja principal característica manifestase pela perda da infância e a entrada no mundo adulto. A problematização aqui apresentada deriva da hipótese de que, quando o universo adolescente adquire status de legitimidade social, que pode ser visto através da mídia e das representações sociais, então a adolescência deixa de ser aquele período de instabilidade e crise; período não familiar cujo único sentido consiste em chegar à fase adulta. A adolescência, uma vez que é representada socialmente em sua própria construção simbólica, não mais poderá ser vista apenas em seu caráter de interface, mas terá legitimado o seu próprio espaço social.

> Palavras-chave: adolescência; representação social; contexto histórico.
1 Mestrando do Programa de Pós-Graduação Educação e Saúde na Infância e Adolescência (ESIA), Universidade Federal de São Paulo (UNIFESP), Brasil. Endereço eletrônico: quirogapesquisa@hotmail.com

2 Professora permanente da Pós-Graduação Educação e Saúde na Infância e Adolescência da UNIFESP, Brasil. Endereço eletrônico: vitalle. dped@epm.br 
A tradição científica, especificamente a partir da psicologia do desenvolvimento de Erikson (1976), postula a adolescência como a fase da vida entre a infância e a idade adulta que culmina com a constituição da identidade. Nesta concepção, a identidade é entendida como o resultado das relações entre as dimensões biológica e social que vão se amalgamando através da vivência do indivíduo ao longo dos anos. Assim, os adolescentes, durante esse período (também conhecido pelas transformaçõos que ocorrem em seu corpo em decorrência da puberdade $)^{1}$ encontram-se numa crise decorrente do processo de construção da identidade e projeção do futuro. No livro Identidade, juventude e crise (ERIKSON, 1976), a partir da famosa expressão "crise de identidade", associa-se o período da adolescência a constantes lutas psicológicas inerentes à formação da identidade. ${ }^{2}$ A este respeito, o psicólogo escreve:

É um período da vida em que o corpo muda radicalmente de proporções, a puberdade genital muda o corpo e a imaginação com toda espécie de impulsos, a intimidade com o outro sexo se inicia e o futuro imediato o coloca diante de um número excessivo de possibilidades e escolhas conflitantes [...] ele deve fazer uma série de seleçóes cada vez mais específicas de compromissos pessoais, ocupacionais, sexuais e ideológicos. (ERIKSON, 1968, p. 132-245).

A citação acima pode ser lida como um quadro sintético do que essa abordagem entendia, na época de sua difusão social, sobre o fenômeno da adolescência. Do ponto de vista das representaçôes sociais, esta interpretação seria a responsável por criar uma forma mais ou menos coesa (consensual) a respeito da imagem do adolescente. Entraremos neste mérito mais adiante. $\mathrm{O}$ que nos interessa compreender, a partir deste olhar, é o modelo reificado da concepção da adolescência que por muitos anos foi aceito como legítimo e sancionado por uma significativa parcela de pesquisadores ${ }^{3}$ (cf. Anna FREUD, 1969; ERIKSON, 1976; ABERASTURY; KNOBEL, 1988). Dada a importância desta abordagem, a forma como o conceito de adolescência se difundia na sociedade confirma-se, por exemplo, a partir da definição do termo pelos dicionários de uso comum. Vejamos nos seguintes exemplos: o termo é apresentado através da ideia de "crise", "instabilidade", "desequilíbrio" e "turbulência”. A Barsa diz: "a adolescência é expressão de um período de desequilíbrio e, via de regra, de conflitos de toda espécie, sobretudo afetivo-emocionais" (BARSA, 1993, p. 89). No dicionário 
Aurélio, o termo aparece como "período da vida humana que sucede à infância, começa com a puberdade, e se caracteriza por uma série de mudanças corporais e psicológicas (estende-se aproximadamente dos 12 aos 20 anos)" (FERREIRA, 2009, p. 54). Monetti e Carvalho (1978) escrevem: "a adolescência, dentro da medicina, foi considerada "terra de ninguém”. O dicionário Houaiss diz que é: "fase do desenvolvimento humano caracterizada pela passagem à juventude e que começa após a puberdade" (HOUAISS; VILLAR, 2009, p. 53). Reconhecese, em todos estes exemplos, a adolescência como o período em que ocorrem as transformações para atingir o estágio adulto, e que se manifestam nos aspectos biopsicossociais que constituem o indivíduo.

Essas transformações permeiam a vida social do indivíduo nesta etapa de construção da identidade. Pode-se inferir, a partir destes exemplos, como a representação social da adolescência passou a ser vinculada a um período de incertezas, caracterizado pelo que se poderia comparar a um espaço fronteiriço entre a forma infantil e a forma adulta. Com efeito, é durante esse período de instabilidade que se configura uma concorrência de situações e experiências pelas quais o adolescente irá se confrontar até chegar à idade adulta. A busca pela emancipação e independência, no entanto, será fortemente marcada pelos condicionantes externos que impregnam a sociedade e o momento histórico em que o adolescente estiver situado.

Por esse motivo, este trabalho se propõe a problematizar a construção da identidade do adolescente através das representações sociais pertencentes ao momento sócio histórico em que ele se encontra. Partimos da hipótese de que a imagem social da adolescência associada à crise seja em consequência desta fonte de exegese científica, responsável pela difusão do conceito através de fortes marcas da epistemologia ascendente da segunda metade do século XX. Nesse sentido, nossa hipótese pressupõe que, em detrimento dessa expansão epistemológica ${ }^{4}$ ocorrida pouco depois da segunda metade do século XX, o conceito de adolescência passou por um processo de transformação que viria a corroborar uma nova fonte de interpretação do fenômeno e consequente forma de representá-lo socialmente.

\section{Delineamento metodológico}

Utilizamos, para tanto, o referencial teórico das Representações Sociais (MOSCOVICI, 2011), cujo pressuposto apregoa que mundo é essencialmente social: 

dada, as imagens e hábitos que nós já aprendemos, as suas recordaçôes que nós preservamos e nossas categorias culturais, tudo isso se junta para fazê-las tais como as vemos. (MOSCOVICI, 2011, p. 33).

As representações sociais constituem uma tentativa do sujeito em transformar algo não familiar em algo familiar: "[...] a finalidade de todas as representaçôes é tornar familiar algo não familiar, ou a própria não familiaridade” (MOSCOVICI, 2011, p. 54). Ora, a princípio, o não familiar é transformado em familiar pelo indivíduo por se tratar de algo indócil, incômodo, desconfortável. Ao assumir como característica do adolescente a construção da identidade, e que se trata de um período de transição da infância para a vida adulta, período também marcado por diversas transformações no corpo, é possível afirmar que nesta etapa vista como um período de crise, o adolescente se encontre na própria ideia geradora de representações sociais, conforme demonstrado na teoria de Moscovici (2011). Para o autor, o processo de formar representações sociais se dá a partir do anormal e do incompreensível - em outras palavras, do não familiar, decorrente da própria ideia de crise. Além disso, as representações sociais têm uma relação íntima com o que se chama de senso-comum:

Sem dúvida, cada fato, cada lugar comum esconde dentro de sua própria banalidade um mundo de conhecimento, determinada dose de cultura e um mistério que o faz ao mesmo tempo compulsivo e fascinante (idem, p. 60) [...] Eu até mesmo iria ao ponto de afirmar que, quanto menos nós pensamos nelas [nas representaçóes sociais], quanto menos conscientes somos delas, maior se torna sua influência (MOSCOVICI, 2011, p. 42).

Isso equivale a dizer que os indivíduos pensam de acordo com o que pensa a sociedade, e não que o indivíduo, ao atribuir em sua fala valor ao senso-comum, abra mão do pensamento. Saber o que pensa a sociedade em determinados campos é um primeiro e importante passo, pois o que pensa o adolescente sobre a adolescência e o próprio adolescente não será um pensamento insular, mas será propiciado pelos meios orientados pela própria sociedade. Portanto, é importante saber o que pensa a ciência sobre o adolescente: isso leva a refletir sobre o campo das observações. Pode-se afirmar que, se o período da adolescência é um estágio de crise, ele necessariamente aparecerá através dos discursos da ciência: o adolescente, neste momento, estará sujeito a projetar uma representação social ou, inversamente, será propiciado por ela. No campo das observaçôes, procuramos as representaçōes sociais do "adolescente", sabendo que elas têm "como seu objetivo 
abstrair sentido do mundo e introduzir nele ordem e percepções, que reproduzam o mundo de uma forma significativa” (MOSCOVICI, 2011, p. 46). É isso o tornar algo familiar: “[...] transformar palavras não familiares, ideias ou seres, em palavras usuais, próximas e atuais” (idem, p. 60) Então, o que se deve perguntar é: qual a imagem familiar do adolescente?

O esclarecimento anterior sobre a caracterização da adolescência através da história, seja como um "período de crise", de "construção de identidade" ou de "rebeldia", pode indicar um rumo. Foi gerado no pensamento social formas diversas, mas complementares, de imagens. Como acontece nas representações sociais, uma representação social, mesmo quando aquilo a que ela se refere desaparece, molda a imagem de acordo com seus preceitos e formas. Este é o processo de ancoragem:

[...] um processo que transforma algo estranho e perturbador, que nos intriga, em nosso sistema particular de categorias e o compara com um paradigma de uma categoria que nós pensamos ser apropriada (MOSCOVICI, 2011, p. 61).

Na problematização que será apresentada na discussão, pretende-se demonstrar que o adolescente, ao invés de associar a sua representação social àquilo que se compreende como processo histórico, qual seja, a do indivíduo sujeito à crise, ou do sujeito em busca da construção da identidade, possa criar agora outras representações sociais, respaldado finalmente pelo percurso sociocultural mais recente, que o legitima como grupo social, e em que o adolescente possui representatividade simbólica sancionada pela mídia, pelo consumo, pelo cinema, pelo esporte, dentre outras coisas produzidas culturalmente.

\section{A importância do contexto nas representaçôes sociais}

É em busca dessa identidade, ou seja, a construção de uma forma individual mais ou menos capaz de dar-lhe condiçôes de conviver numa sociedade que valoriza o indivíduo, 5 que o adolescente contemporâneo irá buscar referências e experimentá-las durante toda essa fase. Desta forma, a mídia, haja vista seu alto poder de penetração social, cumpre papel fundamental no que diz respeito à formação das representações sociais e, consequentemente, da construção de identidade do adolescente (cf. JODELET, 2001; ALLAIN; CAMARGO, 2007; HERZLCH; PIERRET, 2005; ALESSIO; APOSTOLIDIS; SANTOS, 2008; SANTOS; ALESSIO; SILVA, 2009). Heróis de Hollywood, jogadores de futebol 
e atletas, personagens históricos e ficcionais, estereótipos de profissionais, mas também de outros atores sociais, como traficantes, estranhos e arrivistas, serão, com efeito, alguns exemplos de referências em que os indivíduos nesta fase irão ancorar sua identidade, projetando-a para a fase adulta. Mas não só para a fase adulta, pois, como veremos, a adolescência está cada vez mais consolidada como fase legítima - não somente como uma interface.

É preciso, no entanto, considerar que, se esta fase da vida corresponde a período de crise e de instabilidade em que os adolescentes procuram cercar-se de amigos e conviver em grupos, deve-se compreender que, apesar disso, mesmo quando se assume ser este um período de construção da identidade, isto é, de uma forma em direção à vida adulta, não quer dizer que as representações sociais desse período não possuam certa caracterização palpável no cenário contemporâneo. Exemplo disto é a Revista da Turma da Mônica ter, desde o ano 2008, a versão conhecida como Mônica Jovem ${ }^{6}$, em que é representada dentro do universo adolescente.

Deve-se observar, neste sentido, que a adolescência não é, contudo, uma fase destituída de sentido próprio. Pode-se ampliar a lista de exemplos de que o adolescente, em tempos mais recentes, possui referências para se apoiar em personalidades correspondentes a esta fase da vida. Assim, J. D. Salinger ${ }^{7}$ aparece como um dos precursores do reconhecimento dessa fase da vida, ressaltando suas características e situando o adolescente em posição de protagonismo. Num trecho do romance $O$ apanhador no campo de centeio, há um exemplo da imagem que o adolescente cria de si através da leitura de uma matéria científica:

Mas a porcaria do artigo que comecei a ler quase me fez sentir pior ainda. Era sobre os hormônios. Mostrava a aparência que a gente deve ter - a cara, os olhos e tudo quando os hormônios estão funcionando direito, e eu estava todo ao contrário. Estava parecendo exatamente com o sujeito do artigo, que estava com os hormônios todos funcionando errado. Por isso comecei a ficar preocupado com meus hormônios. Aí li outro artigo, sobre a maneira pela qual a gente pode saber se tem câncer ou não. Dizia lá que, se a gente tem alguma ferida na boca que demora a sarar, então isso é sinal de que a gente provavelmente está com câncer. E eu já estava com aquele machucado na parte de dentro do lábio há umas duas semanas [...] Calculei que devia morrer dentro de uns dois meses, já que estava com câncer. Foi mesmo. Eu estava certo de que ia morrer. Evidentemente, essa ideia não me deixou muito satisfeito (SALINGER, 1965, p. 138).

Esse trecho exemplifica bem o que Moscovici quis dizer ao afirmar serem as representações de origem objetivadas ou consensuais. Neste caso, quando o adolescente se vê representado por uma revista, logo relaciona sua vida a esta 
etapa e então se vê condenado aos grilhões do conhecimento científico. Com efeito, Holden Caulfield (o protagonista) se vê aprisionado por questóes exteriores que se impõem sobre sua existência de forma coercitiva, num tom quase punitivo e gerador de culpa. O adolescente representado por Salinger é extremamente negativo, diante de um mundo que não lhe confere nenhum espaço de partilha, mas o sufoca e o oprime a cada instante. $\mathrm{O}$ que interessa neste artigo, no entanto, não está no simbolismo presente da obra de Salinger, mas na influência que sua obra logrou alcançar sobre a geração de adolescentes, corroborando a representação social do adolescente em sua condição de crise. Há, no entanto, um indício de mudança. $\mathrm{O}$ adolescente, nessa obra, ocupa pela primeira vez na literatura o papel de protagonista e herói. Quer dizer, com Salinger, o adolescente passou a ser representado socialmente. Isso entra em consonância imediata com a hipótese de que a legitimidade desta etapa da vida amortiza a ideia de crise e instabilidade, e retira do adolescente o idealismo voltado à vida adulta. Em síntese, pode-se dizer que Salinger inaugura e instaura nesse espaço fronteiriço um campo de representação, colocando a figura do adolescente em primeiro plano. A adolescência, em sentido conceitual, adquire então certa plasticidade, que irá legitimá-la como período significativo e específico da vida, e não somente como uma "passagem" de uma etapa à outra.

Se a adolescência é, de modo geral, uma fase de instabilidade na qual o que se busca, em última instância, é a criação de uma forma que será consagrada somente quando atingir a idade adulta, então quando o adolescente adquire o status de protagonista social, nota-se que a criação de identidade deste adolescente será agora facilitada pelo reconhecimento de outro adolescente, e não estará condicionada a referenciar-se necessariamente ao mundo adulto.

$\mathrm{O}$ período da adolescência, com efeito, adquirirá legitimidade e status de reconhecimento social que dará sanção aos sujeitos para adquirirem um comportamento específico da idade, colocando em questão o conceito de que ela é simplesmente uma interface entre dois universos bem definidos: o infantil e o adulto. $\mathrm{O}$ adolescente estará sob a salvaguarda de uma construção simbólica localizada no mundo, que será também a expressão de que a fronteira entre a adolescência e a vida adulta dissolveu-se, e que o adolescente pode, então, ser a expressão do herói de um tempo, seja quando comparamos o primeiro Superman, de 1938 (um homem de meia idade com traços de adulto bem definidos) do 
último, (um Clark Kent muito mais jovem e por isso mais próximo do universo adolescente), seja através dos programas humorísticos como o CQC, ${ }^{8}$ onde se faz presente a expressão de um humor colegial; ou da presença de jogadores como Neymar - figura bastante comum em capas de revistas destinadas ao público adolescente. Pode-se também referenciar esta ideia através da literatura adolescente, com o sucesso dos livros de Harry Potter, de J. K. Rowling, dos livros de vampirismo e das mídias virtuais.

Se a sociedade anteriormente desconsiderava o aspecto sui generis da adolescência, atribuindo-lhe importância apenas de "passagem" (SCHOENFERREIRA et al., 2010; PERES; ROSENBURG, 1998), agora parece que o cenário não só favorece, mas acresce a cada momento uma simbologia destinada a este público. Se atualmente a adolescência adquire certa legitimidade de que anteriormente carecia, é provável que a escola, nesse sentido, deva considerar essa mutação sócio-historica; isto é, deva considerar o papel antes alienado que este cumpria para o de protagonista potencial. Assim, a questão da construção da identidade não mais será referenciada através de modelos adultos; agora, o adolescente poderá ancorar-se na representação de outro adolescente, e isso constituirá o universo adolescente, tanto como existe o universo infantil e o adulto. A própria ideia de "interseç̧ão" ou de "passagem" tornam-se ideias obsoletas ou não mais cabíveis, pois agora o adolescente encontra lugar referenciado por um simbolismo específico dessa faixa etária.

Entretanto, se o adolescente em nossa sociedade atual não mais se encontra como um apátrida cultural, isto é, conta agora com uma sociedade que o representa em forma de herói, que lhe confere uma condição sólida de representação de si, que o coloca como protagonista de personagens de ficção, e que por isso o legitima, então o "desequilíbrio", a "crise", estariam inscritos em visões de certa tradição científica de épocas em que o adolescente ainda não possuía a representatividade que lhe é conferida atualmente. Como sabemos, a ciência se faz através da superação e renovação permanentes. No livro Adolescência, de Monetti e Carvalho (1978), ao refletirem sobre a masturbação, por exemplo, escrevem:

A masturbação foi alvo de muita discussão, se prejudicial ou não. A sua inocuidade tem sido demonstrada, mas durante muito tempo predominava a ideia de seus malefícios, afora os termos de vício e perversão que a acompanhavam.

Tal modo de encarar, irreal e antiquado, é que, na realidade, perturbou muitas geraçôes de adolescentes, com sentimentos de culpas e angústias. [...] A masturbação é uma 
atividade normal, temporária, própria daquela fase etária e que tende a desaparecer no momento em que a atividade heterossexual se torne acessível. Convém insistir sobre o caráter momentâneo destas atividades (MONETTI; CARVALHO, 1978, p. 52).

A análise desta passagem é interessante, tanto no que se refere à mutabilidade da ciência, quanto aos preconceitos e valores que estão a elas arraigados, bem como as formas como ela interfere na orientação do comportamento moral das pessoas. Os autores assumem ser a masturbação uma parte propedêutica à prática sexual propriamente dita. A afirmação dos autores refere-se ao disciplinamento dos corpos, como observou Foucault (1999):

De um lado, a sexualidade, enquanto comportamento exatamente corporal depende de um controle disciplinar, individualizante, em forma de vigilância permanente (e os famosos controles, por exemplo, da masturbação que foram exercidos sobre as crianças desde o fim do século XVIII até o século XX, e isto no meio familiar, no meio escolar, etc., representam exatamente esse lado do controle disciplinar da sexualidade); e depois, por outro lado, a sexualidade se insere e adquire efeito, por seus procriadores, em processos biológicos amplos que concernem não mais ao corpo do indivíduo, mas a esse elemento, a essa unidade múltipla constituída pela população. (FOUCAULT, 1999, p. 299).

Quando se enfatiza o caráter momentâneo da atividade masturbatória, denota-se a preocupação mais com a forma de punição educativa e moral do que na de apresentarem um resultado obtido por meio da ciência. É possível observar não só o caráter mutável da ciência, como sua adequação ao tempo social em que se inscreve. Indica a efemeridade do conhecimento científico e seu caráter modulável em consonância com aspectos mais gerais da sociedade, como a moral. Buscamos, através desses exemplos, problematizar a representação social da adolescência como um período de crise.Nosso argumento aponta que tal período talvez esteja mais relacionado à ausência de uma cultura adolescente do que a uma crise fatalmente indiscutível.

\section{Considerações finais}

Logramos, ao longo deste trabalho, demonstrar como, através da consolidação do universo adolescente, a sociedade pode referenciar o indivíduo que se encontra neste período. Assim, uma vez que esta fase deixa de ser uma intersecção entre períodos, o espaço representacional do adolescente será povoado de toda classe de símbolos que a sancionam e a legitimam. Com efeito, talvez seja antiquado referir-se a esta fase como um período de turbulências ou crise. Tal hipótese 
encontra resposta no processo de ancoragem, gerador de representaçôes sociais (MOSCOVICI, 2011). Quando o adolescente não mais necessita ancorar uma representação de si sobre um adulto, mas pode ancorar-se num mundo construído para ele, então essa crise deixa de existir para tornar-se possível; isto é, o adolescente não mais precisará esperar que passe esta dolorida etapa de espinhas e trajes constrangedores, pois ele será, com efeito, um indivíduo em fase de mutação, mas uma mutação situada agora num processo legítimo de construção, no qual não poucas vezes concorre a protagonista da sociedade em sua total dimensão.

$\mathrm{Na}$ literatura, alguns trabalhos sugerem que a representação social $\mathrm{da}$ adolescência se apresenta de maneira mais ou menos ambígua, ora pendendo para representações ancoradas em ideias como "curtir a vida", "felicidade", "liberdade", "rebeldia", "sexo", namoro", ora pendendo para temas como "responsabilidade nos estudos”, “justiça social”, "solidariedade” (PAIXÃO, 2011; SALLES, 1995; SANTOS; NETO; SOUZA, 2011). A ambiguidade presente nessas representações, se olharmos mais atentamente, coincidem e refletem as transformaçôes sociais e históricas do momento. Sob esse ponto de vista, podemos perceber que as categorias referentes a "curtir a vida", "felicidade" etc. inscrevem-se num período histórico de liberdade de expressão pós-regimes totalitários, associando-se a essa ideia as representações mais demarcadas da anarquia juvenil, do uso de substâncias tóxicas e da liberação sexual. O outro grupo de representações está associado às transformações do mundo no cenário econômico e político mais atual, isto é, a ideia da responsabilidade sobre o meio ambiente, o uso consciente da água, a tolerância étnica e sexual, etc. Salles (1995), a este respeito, apresenta uma série de estudos que apontam para essa direção. A autora apresenta os seguintes quadros representativos:

$\mathrm{Na}$ década de 60 , predominou a ideia de adolescência como época de contestação social. A ética social pela qual se via o adolescente era a de que este era transgressor, descontraído, liberado, rebelde, contestador de normas. Tomava-se como referencia o jovem amoral, drogado e moderno (SALLES, 1995, p. 30).

E compara:

Estudos das décadas de 70 e 80 mostram que o jovem compartilha dos valores sociais, aceitando muitas vezes, sem questionar, as normas e as regras sociais, almejando status social, situação financeira estável e constituir família pelo casamento. (SALLES, 1995, p. 30). 
Essas duas citações são cruciais para entendermos o processo pelo qual as representações sociais se formam em diferentes contextos históricos. Nossa proposta, neste sentido, consistiu em problematizar não diretamente as representações da adolescência na contemporaneidade, mas visualizar de que modo sentidos sociais diversos influenciam na geração de novas formas de representações.

Influenciada pela ciência tradicional, a adolescência foi frequentemente associada por ancoragem a representaçôes de "instabilidade", "crise", "turbulência", "desequilíbrio", dentre outras, relegando ao adolescente a busca e construção de sua identidade. Subentende-se, a partir desta perspectiva, que esta é uma fase de intersecção entre a infância e a vida adulta, isto é, um período de fronteira entre duas etapas simbolicamente legítimas. Além disso, subjaz nesta concepção a ideia de que a adolescência adquire sentido na medida em que o indivíduo idealiza o próprio futuro. Vitalle e Medeiros (2008) reforçam:

A adolescência é um momento da vida absolutamente fértil, de descobertas im-
pressionantes, de criatividade e prazer. Entretanto, ela é também dolorosa, o jo-
vem tem um futuro a ser projetado (o que faz dele um grande sonhador), um pas-
sado que deve ser revisto e, consequentemente, um adeus à infância. (VITALLE,
MEDEIROS, 2008, p. 11).

Ao se reconhecer a adolescência como etapa de incertezas e de projeção de período de transição entre dois universos consensualmente representados socialmente - o da infância e o da vida adulta - infere-se que esse período carecia de referenciais próprios e legítimos para essa etapa. Nesta reflexão, procuramos mostrar através de alguns exemplos que, no decorrer do processo histórico até nossos dias, a adolescência passou de uma etapa de alienação e obscurantismo para outra de reconhecimento e criação de identidades próprias. Ademais, como logramos demonstrar, as representações sociais desta fase da vida não são rígidas, mas determinadas pelas mudanças e condicionantes sociais e históricos da época em que este se encontra. O rótulo de "crise de identidade" - expressão cunhada por Erikson (1987) - não somente sugere uma ideia reificada e estanque da adolescência, como promove um cabedal de representaçôes associadas à ideia de crise, isto é, um estado amorfo (tanto do ponto de vista biológico quanto do social) e caótico, cuja saída inevitável resulta em outra ancoragem clássica, conhecida por todos como a rebeldia. A produção de sentidos sociais, como se pode observar, encontra-se fortemente subsumida ao discurso científico da época. 
Aliás, que a adolescência tenha sido interpretada de modo cristalizado como um período entre a infância e a idade adulta, fortemente marcado pela ideia de crise de identidade, não quer dizer, todavia, que não haja carecido de representações sociais. Ora, a própria expressão "crise de identidade" foi a base que por algum tempo sustentou as demais representaçôes sociais sobre a adolescência. A aparente ideia de intersecção entre as duas etapas que ladeiam a adolescência (infância e idade adulta), conforme buscamos defender em nosso argumento, criou uma ideia de lacuna, como se as representaçóes sociais desse período expressassem uma espécie de salto entre estes dois campos solidamente definidos. Em outras palavras, é como se, a partir desta concepção, o adolescente, comprimido entre as forças da infância e da vida adulta, saltasse para fora de sua condição de crise, desse âmago escuro e caótico, e manifestasse uma rebeldia não sem causa, mas às expensas da própria condição a que fora submetido sob os auspícios do pensamento científico de sua época.

Esse espaço intermediário entre a infância e a idade adulta, em tempos mais atuais, passaria a ser colonizado por uma onda de simbologia própria, conforme pode ser observado na sociedade, como na mídia, no cinema e nos esportes. $\mathrm{O}$ período da adolescência, antes carente de referências e representaçóes sociais positivas, quando visto sob uma perspectiva mais hodierna, adquire seu próprio escopo simbólico. Com efeito, a ideia de crise, bem como de instabilidade ou turbulência, talvez não mais caiba como a melhor expressão para falar desse período de transformaçôes. $\mathrm{O}$ adolescente, se legitimado e sancionado, possui representatividade específica. Desta forma, estamos caminhando para a afirmação de que a adolescência corresponda a uma etapa do desenvolvimento do indivíduo, não se deixando de lado a constatação de que em nossa sociedade, o adolescente encontra-se agora situado, não mais lhe restando o papel passivo e alienado até o momento em que esse período seja encoberto pela fase adulta, mas como uma parte da vida repleta de significados, protagonismo e produção cultural própria. ${ }^{9}$

\section{Referências}

ABERASTURY, A.; KNOBEL, M. Adolescência normal. Porto Alegre: Artes Médicas, 1988. BARSA, Enciclopédia. Encyclopaedia Britannica. V. 2. São Paulo: Encyclopaedia Britannica Consultoria Editorial, 1993.

BAUMAN, Z. O mal-estar da pós-modernidade. Rio de Janeiro: Jorge Zahar, 1998. 
CAVALCANTE, M.J.M. O mito da rebeldia na juventude: uma abordagem sociológica.

Educação em debate. Fortaleza, n. 13, p. 11-23, jan/jun. 1987.

ERIKSON, E. Identidade, juventude e crise. $2^{\text {a }}$ ed. Rio de Janeiro: Zahar, 1976.

FERREIRA, A.B.H. Novo Dicionário Aurélio da Lingua Portuguesa. 4. Ed. Curitiba: Positivo, 2009.

FORACCHI, M.A. A juventude na sociedade moderna. São Paulo: Pioneira, 1972.

FOUCAUlT, M. Em Defesa da Sociedade: Curso no Collège de France (1975-1976). São Paulo: Martins Fontes, 1999.

FREUD, A. La adolescencia encuanto perturbacion del desarrollo. In: CAPLAN, L. (Org.). El desarrollo del adolescente. Buenos Aires: Paidós, 1969. p. 15-24.

HERZLICH, C. La représentacion sociale. In: MOSCOVICI, S. (Org.). Introduction a la psycologie sociale. V.1. Paris: Larousse, 1972. p. 303-25.

HOUAISS, A.; VILLAR, M.S. Dicionário Houaiss da lingua portuguesa. Rio de Janeiro: Objetiva, 2009.

KNOBEL, M. Um enfoque psico-social de la juventude contemporânea. Revista Argentina de Psiquiatria y Psicologia de la Infancia y la Adolescencia. Buenos Aires, n. 1, p. 113-22, 1971. MONETTI, V.; CARVALHO, P.R. Adolescência (aspectos médico-sanitários e psicossociais). São Paulo: Instituto de Saúde, 1978.

MOSCOVICI, S. Representaçôes Sociais. Investigaçōes em psicologia Social. Rio de Janeiro: Vozes, 2011.

MASSERMAN, J.H. Extravagancias y virtudes de la juventude americana. Revista Argentina de Psiquiatria y Psicologia de la infancia y la adolescencia. Buenos Aires, n. 1, p. 157-76, 1971.

NASCIMENTO, S.R.G. Atitudes e valores de adolescentes da cidade de São Paulo: um estudo com alunos de $2^{\circ}$ grau. Dissertação (Mestrado em Psicologia Social) - Pontifícia Universidade Católica de São Paulo, São Paulo, 1978.

OESTER, R.; DREHER, E. Jugendalter. In: OERTER, R.; MONTADA, L. Entwicklungspsycologie. Weinheim: Beltz, 2002. p. 258-318.

PAIXÃO, D.L.L. A representação da adolescência e as políticas sociais de educação e justiça. In: Seminário Internacional de representações sociais, subjetividade e educação, I., Anais... Curitiba: SIRSSE, 2011.

PASCHOAL, N. O discurso do adolescente: um enfoque fenomenológico hermenêutico. Tese (Doutorado em Educação) - Pontifícia Universidade Católica de São Paulo, São Paulo, 1985. PERES, F.; ROSENBURG, C.P. Desvelando a concepção de adolescência/adolescente presente no discurso da saúde pública. Saúde soc., v. 7, n. 1, p. 53-86, 1998.

REINOSO, D.G. Adolescencia, família y sociedade. Revista Argentina de Psiquiatria y Psicologia de la infância y la adolescência. Buenos Aires, n. 1, p. 95-112, 1971. 
SALLES, L.M.F. A representação social do adolescente e da adolescência: um estudo em escolas públicas. Cad. Pesq. São Paulo, n. 95, p. 25-33, ago. 1995.

SALINGER, S.D. O apanhador no campo de centeio. Rio de Janeiro: Autor, 1965.

SANTOS, M.F.S.; ACIOLI NETO, M.L.; SOUZA, Y.S.O. Adolescência em revistas: um estudo sobre representações sociais. Psicologia: Teoria e Prática, v. 13, n. 2, p. 103-113, 2011. SCHOEN-FERREIRA, T.H.; AZNAR-FARIA, M.; SILVARES, E.F.M. Adolescência através dos séculos. Psic. Teor. e Pesq., v. 26, n. 2, p. 227-34, 2010.

SUÁREZ, A.S. Crise de identidade na adolescência: breve análise e implicações para a práxis religiosa segundo a teoria de Erik Erikson. ACTA Cientifica-Ciências Humana, v. 2, n. 9, 2005.

VITALLE, M.S.S.; MEDEIROS, E.H.G.R. Adolescência: uma abordagem ambulatorial. Barueri: Manole, 2008.

\section{Notas}

${ }^{1}$ Conceitualmente, a adolescência caracteriza-se por alterações em diversos níveis - físico, mental e social - e representa, para o indivíduo, um processo de distanciamento de formas de comportamento e privilégios típicos da infância e de aquisição de características e competências que o capacitem a assumir os deveres e papéis sociais do adulto (OERTER; MONTADA, 2002).

${ }^{2}$ Para Erikson, a formação da identidade é um fenômeno social marcado por um "processo de reflexão e observação simultâneas" que atinge a totalidade do universo psíquico e no qual o indivíduo julga a si próprio a partir do julgamento dos outros (ERIKSON, 1976).

${ }^{3}$ Num artigo de Salles acerca das representações sociais do adolescente, há uma importante observação sobre a influência desta concepção cristalizada da adolescência. A autora reflete: "A adolescência, de acordo com a bibliografia da área, é uma época de transgressões ao fim da qual se espera que o jovem deixe a escola, saia da família de origem, se case e tenha um emprego. As teorias sobre a adolescência de modo geral, qualificam-na como uma fase intermediária da vida, na qual o jovem se prepara para ser adulto, caracterizando-se por ser uma época de ajustamentos sociais, profissionais e sexuais e de luta pela sua emancipação dos pais, o que implica uma redefinição de si mesmo" (SALLES, 1995,p. 30).

${ }^{4}$ Referimo-nos à grande diversidade de autores como Elias, Bourdieu, Derrida, Foucault, Guattari, Lacan, Arendt, Castel e Bauman - somente para citar alguns, e a grande diversidade de correntes conhecidas como pós-estruturalistas e suas diversas denominaçōes: desconstrução, microssociologia, microhistória, etc. - que coincidem na incidência do olhar sobre os fenômenos sob uma perspectiva menos ideal, isto é, menos cristalizada e mais próxima do entendimento humano como o resultado inacabado (e em certo ponto arbitrário) de um processo histórico.

${ }^{5}$ Bauman (2007), em Vida líquida, discute a questão do indivíduo inserido na sociedade pós-moderna. Numa passagem, o autor escreve: "Numa sociedade de indivíduos - nossa "sociedade individualizada" -, de todos se exige que sejam indivíduos, e de fato, é isso que nós desejamos e tentamos." (BAUMAN, 2007, p. 27). 
${ }^{6}$ Turma da Mônica Jovem é um gibi em estilo mangá, de Mauricio de Sousa. Trata-se de uma evolução dos personagens de Turma da Mônica, agora adolescentes. As revistas se apresentam em formato semelhante ao dos mangás lançados originalmente no Japão.

${ }^{7}$ Em 1951, publica seu primeiro romance, The catcher in the rye ( $O$ apanhador no campo de centeio, no Brasil, e À espera no centeio ou Uma agulha no palheiro, em Portugal), que se torna um sucesso imediato. Sua descrição da alienação da adolescência e da inocência perdida através do seu protagonista, Holden Caulfield, serviu de influência para toda uma geração de novos leitores, especialmente adolescentes.

${ }^{8}$ CQC: sigla que significa "custe o que custar". É um programa humorístico brasileiro, de frequência semanal, produzido pela Eyeworks e exibido pela Rede Bandeirantes desde 17 de março de 2008.

${ }^{9}$ F.L. Quiroga participou da concepção original da pesquisa, da elaboração do projeto, do levantamento bibliográfico, da análise da literatura e da elaboração do manuscrito, e aprovou a versão final. M.S.S. Vitalle participou da concepção original da pesquisa, da elaboração do projeto, do levantamento bibliográfico, da análise da literatura e da elaboração do manuscrito e aprovou a elaboração final do manuscrito. 
Adolescents and their social representations: notes on the importance of the historical context This study aims to discuss the modes of social representation of adolescence. Scientific tradition, especially from Erikson (1976), favored the social representation according to which adolescence is a period of transition between childhood and adulthood, ie, a period marked by instability, crisis and turbulence whose main characteristic is manifested by the loss of childhood and the beginning of adult life. The discussion presented here derives from the assumption that, when the adolescent universe acquires social status of legitimacy, which can be seen through the media and social representation, then adolescence is no longer that period of instability and crisis; unfamiliar period which only sense is to reach adulthood. Adolescence, as it is represented in its own socially symbolic construction, can no longer be seen only as an interface, but has legitimated its own social space.

Key words: adolescence; social representation; historical context. 